\title{
CARACTERIZAÇÃO DO PROGRAMA SAÚDE NA ESCOLA ${ }^{1}$
}

\author{
Ricardo Hélio Chaves Maia \\ Especialização em Cardiologia (UECE), Graduação em Medicina (UFC) \\ Universidade Estadual do Ceará / ricmaia@hotmail.com \\ Keila Andrade Haiashida
Pós-Doutorado em Educação (UFPB), Doutorado em Geografia (UECE), Mestrado em Educação (UFC), Graduação em Pedagogia (UFC)

Universidade Estadual do Ceará / keila.haiashida@uece.br

\begin{abstract}
RESUMO: O Programa Saúde na Escola (PSE) integra à Política Nacional de Atenção Básica (PNAB). Assim, o objetivo do estudo foi caracterizar o PSE. Para tanto, realizamos pesquisa bibliográfica e documental. O PSE tem a intenção de contribuir para formação integral dos alunos através da promoção, prevenção e atenção à saúde. Dessa forma, os beneficiados pelo programa são os estudantes da Educação Básica, gestores e professores da educação e saúde, estudantes da Rede Federal de Educação Profissional e Tecnológica e da Educação de Jovens e Adultos (EJA). Para viabilizar os objetivos do PSE, foram definidos cinco componentes: a) avaliação das condições de saúde das crianças, adolescentes e jovens da rede pública; b) promoção da saúde e de atividades de prevenção; c) educação permanente e capacitação dos profissionais da educação e da saúde e de jovens; d) monitoramento e avaliação da saúde dos estudantes; e) monitoramento e avaliação do programa.
\end{abstract}

Palavras-chave: Saúde. Educação. Atenção Básica.

\section{Introdução}

A Política Nacional de Atenção Básica (PNAB) resulta de experiências na área de saúde e visa consolidação do Sistema Único de Saúde (SUS). Uma das conquistas atribuídas ao sistema de Atenção Básica (AB) no Brasil é seu alto grau de descentralização e capilaridade.

Assim, a PNAB teve como consequência a criação de vários programas e serviços. Nesta pesquisa assumimos como objeto de estudo o Programa Saúde na Escola (PSE), instituído pelo Decreto Presidencial n 6.286, de 05 de Dezembro de 2007 com a finalidade de contribuir para formação integral dos estudantes da rede básica por meio de ações de prevenção, promoção e atenção a saúde.

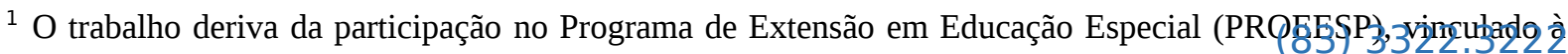
Pró-Reitoria de Extensão da UECE e coordenado pela orientadora do estudo.contato@fipedbrasil.com.br 
O objetivo do estudo foi caracterizar o PSE que representa uma iniciativa de articulação em Saúde e Educação.

Para alcançar o objetivo proposto, procedemos à uma pesquisa bibliográfica na área de saúde e educação em autores como: Dantas (et al, 2007); Mendonça (2009); Rezende, Dantas (2009) e Rezende, Dantas e Pedrosa (2009) e pesquisa documental, tendo como principais fontes a Política Nacional de Atenção Básica (2012), os Cadernos de Atenção Básica (2009) e o Decreto Presidencial n ${ }^{\circ} 6.286$ (2007).

\section{Interfaces entre saúde e educação}

A Política Nacional de Atenção Básica (PNAB) integra a Rede de Atenção à Saúde, orientada pelos princípios da "universalização, acessibilidade, vínculo, continuidade do cuidado, integralidade da atenção, responsabilização, humanização, equidade e participação social” (BRASIL, 2012, p. 11).

Vinculados à Rede de Atenção à Saúde temos diversas ações, programas e estratégias como:

- Academia da Saúde;

- Amamenta e alimenta Brasil;

- Brasil sorridente;

- Consultórios na rua;

- Saúde da família;

- SAMU;

- Nutri SUS

- NASF;

- Farmácia Popular

- Programa Saúde na Escola.

Conforme explicitado no estudo, enfatizamos o PSE para Mendonça (2009) a integração de práticas nas áreas de saúde e educação possibilita uma importante troca de saberes e a ressignificação dessa relação. Saúde e educação tem vivenciado aproximações e distanciamentos e destes tem surgido algumas experiências de encontros e desencontros. $\mathrm{O}$ PSE pode ser considerada uma experiência de encontro entre saúde e educação.

A saúde tem sido associada historicamente ao surgimento de doenças, sua prevenção e cura. Isso reflete a hegemonia do modelo biomédico que tefo Berribea 
muito tempo o desenvolvimento das práticas de saúde no Brasil e no mundo, desconsiderando a capacidade de as pessoas assumirem o cuidado e o controle sobre o corpo e a vida, delegando-os aos profissionais de saúde (REZENDE E DANTAS, 2009, p. 07).

O resultado dessa hegemonia do modelo biomédico foi o distanciamento com outros setores e áreas do conhecimento, imprescindíveis para compreensão da saúde. Ao articularmos saúde e educação saúde passa a ser concebida em uma perspectiva integral, como processo, que incorpora aspectos das subjetividades e a noção de direito, de qualidade de vida. Dessa forma, conceber o processo saúde e doença em uma perspectiva integral pressupõe, também, a compreensão de seus determinantes. Saúde e doença, nesse enfoque, não devem ser percebidos como conceitos opostos, já que ambos se referem à produção da vida, estando inseridos em contextos históricos, sociais, econômicos, políticos, éticos, ambientais e culturais (DANTAS, REZENDE e PEDROSA, 2009).

\section{O Programa Saúde na Escola: resultados iniciais}

Ao abordarmos o campo da saúde coletiva deparamo-nos com a inserção da saúde em uma realidade social complexa, daí a necessidade de considerá-la como um campo interdisciplinar, articulado a uma totalidade social permeada de contradições. A constituição de espaços dialógicos que possibilitem a interlocução de saberes e práticas parece configurarse como estratégia de superação dessas situações-limite (DANTAS et al., 2007).

O PSE resulta do trabalho integrado entre o Ministério da Saúde e o Ministério da Educação, na perspectiva de ampliar as ações específicas de saúde aos alunos da rede pública de ensino: Ensino Fundamental, Ensino Médio, Rede Federal de Educação Profissional e Tecnológica, Educação de Jovens e Adultos (BRASIL, 2007).

Os principais objetivos deste Programa são (BRASIL, 2009, p. 12 e 13):

I - Promover a saúde e a cultura de paz, reforçando a prevenção de agravos à saúde;

II - Articular as ações da rede pública de saúde com as ações da rede pública de Educação Básica, de forma a ampliar o alcance e o impacto de suas ações relativas aos estudantes e suas famílias, otimizando a utilização dos espaços, equipamentos e recursos disponíveis;

III - Contribuir para a constituição de condições para a formação integral de educandos; 
IV - Contribuir para a construção de sistema de atenção social, com foco na promoção da cidadania e nos direitos humanos;

V - Fortalecer o enfrentamento das vulnerabilidades, no campo da saúde, que possam comprometer o pleno desenvolvimento escolar; VI - Promover a comunicação entre escolas e unidades de saúde, assegurando a troca de informações sobre as condições de saúde dos estudantes;

VII - Fortalecer a participação comunitária nas políticas de Educação Básica e saúde, nos três níveis de governo.

O $3^{0}$ artigo do Decreto 6.286 (2007) explicita que o PSE constitui estratégia para a integração e a articulação permanente entre as políticas e ações de educação e de saúde, com a participação da comunidade escolar, envolvendo as equipes de saúde da família e da educação básica. No artigo $4^{0}$ do mesmo decreto vemos que as ações em saúde previstas no âmbito do PSE considerar o a atenção, promoção, prevenção e assistência, e serão desenvolvidas articuladamente com a rede de educação pública básica e em conformidade com os princípios e diretrizes do SUS.

O planejamento das ações do PSE deverá considerar:

I - o contexto escolar e social;

II - o diagnóstico local em saúde do escolar; e

III - a capacidade operativa em saúde do escolar.

\section{Considerações Finais}

É importante refletir sobre a caminhada e o processo de articulação entre saúde e educação, o que nos remete a pensar as formas de integração entre dois campos que estão próximos no cotidiano, mas distantes na compreensão de um em relação ao outro. 
Ações, serviços, projetos e programas como o PSE permitem uma aproximação necessária entre saúde e educação e demandam atividades integradas, que podem e devem levar a uma melhoria da qualidade de vida dos beneficiados, por intermédio de ações pedagógicas preventivas.

Dessa forma, esperamos com o estudo caracterizar o PSE e dar visibilidade ao programa para os profissionais de saúde e educação que ainda não estão familiarizados com a articulação entre essas duas áreas de conhecimento.

\section{Referências Bibliográficas}

BRASIL. Decreto 6.286 que institui o Programa Saúde na Escola. Brasília: Ministério da Educação e da Saúde, 2007.

Cadernos de Atenção Básica. Brasília: Ministério da Educação e da Saúde, 2009.

DANTAS, V. L. A.; LINHARES, A. M. B.; ANDRADE, L. O. M.; PORTO, T. C. A. Violência como situação limite nas rodas das Cirandas da Vida em Fortaleza, Ceará. Divulgação em Saúde em Debate, v. 39, p. 68-81, 2007.

MENDONÇA, Rosa Helena. Aos professores e professoras. In Saúde e Educação: uma relação possível e necessária. Brasília: Ministério da Educação (Salto para o Futuro), 2009.

REZENDE, Regiane; DANTAS, Vera Lúcia de Azevedo. Apresentação da série Saúde e educação: uma relação possível e necessária. In Saúde e Educação: uma relação possível e necessária. Brasília: Ministério da Educação (Salto para o Futuro), 2009.

REZENDE, Regiane; DANTAS, Vera Lúcia de Azevedo; PEDROSA, José Ivo dos Santos. Integração das Políticas de Saúde e Educação. In Saúde e Educação: uma relação possível e necessária. Brasília: Ministério da Educação (Salto para o Futuro), 2009. 